\title{
Antalya il merkezinde kronik spontan ürtikeri olan çocukların klinik ve demografik verilerinin değerlendirilmesi
}

\author{
Evaluation of clinical and demographic data of children with chronic spontaneous \\ urticaria in Antalya province
}

\author{
Serkan Filiz
}

\section{Özet}

Amaç: Çalışmada, ilimizdeki çocuklarda kronik spontan ürtiker (KSÜ) etiyolojisinde rol oynayabilecek faktörler ve ilişkili klinik ve laboratuvar bulguların araştırıması amaçlandı.

Gereç ve yöntem: Kliniğimizde KSÜ tanısı alan 7-17 yaş arası 107 hastanın kayıtları retrospektif olarak incelendi. KSÜ'lü hastaların demografik ve klinik özellikleri, laboratuvar bulguları, atopi, enfeksiyon, otoimmüniteye yönelik tetkikleri değerlendirildi. Ek olarak hastalık şiddetinin değerlendirilmesi için Ürtiker Aktivite Skoru (ÜAS7) ve hastalık kontrolünün değerlendirilmesi için Ürtiker Kontrol Testi (ÜKT) uygulandı.

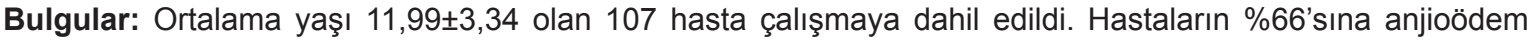
eşlik etmekteydi. Ürtiker ortanca süresi 8 (2-72) ay idi. Hastaların \%36'stına alerjik hastalıklar eşlik etmekte idi. Hastaların \%12'sinde astım ve \%21'inde alerjik rinit öyküsü vardı. Olguların \%33'ünde inhalen duyarlılığı ve \%6,5'inde besin alerjen duyarlılığı saptandı. Yüzde 16,8'indee antinükleer antikor (ANA) pozitifliği, \%6,5'inde tiroid otoantikor varlığı, \%3'nde idrar yolu enfeksiyonu, \%1,9'unda helikobakter pylori pozitifliği ve \%1,9'unda

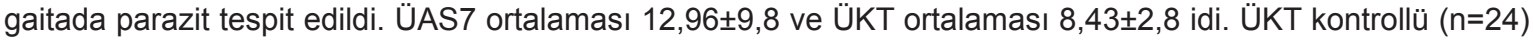
ve kontrolsüz $(n=83)$ olan hastalar karşılaştırıldığında; yaş cinsiyet, anjioödem varlığı, hastalık süresi ve ANA pozitifliği açısından gruplar arasında anlamlı bir fark saptanmadı (sırasıyla, $p=0,842, p=0,646, p=0,347, p=0,590$, $p=0,316)$.

Sonuç: Çocuklarda KSÜ etiyolojisinde atopik hastalıklar, enfeksiyonlar, paraziter enfestasyonlar yer tutarken çoğu vakada tanı idiyopatik olarak kalmaktadır.

Anahtar kelimeler: Kronik ürtiker, çocuklar, otoimmün tiroidit, ürtiker kontrol test, ürtiker aktivite skorlaması.

Serkan F. Antalya il merkezinde kronik spontan ürtikeri olan çocukların klinik ve demografik verilerinin değerlendirilmesi. Pam Tıp Derg 2020;13:129-135.

\begin{abstract}
Purpose: The aim of the study was to investigate the etiology of chronic urticaria in children and the related clinical and laboratory findings in our city.

Materials and methods: One hundred-seven patients aged between 7-17 years who were diagnosed with chronic spontaneous urticaria (CSU) in our clinic were retrospectively reviewed. Demographic and clinical characteristics, laboratory findings, atopy, infection, and autoimmunity tests of patients with CSU were evaluated. In addition, Urticaria Activity Score (UAS) and Urticaria Control Test (UCT) were applied to evaluate disease severity.

Results: A total of 107 patients with a mean age of $11.99 \pm 3.34$ were enrolled in the study. Angioedema was associated with $66 \%$ of the patients. The median duration of urticaria was 8 (2-72) months. Allergic diseases were associated with $36 \%$ of the patients. Twelve percent of patients had asthma and $21 \%$ had allergic rhinitis. Inhaler sensitivity was detected in $33 \%$ of cases and food allergen sensitivity in $6.5 \%$ of cases. Antinuclear antibody (ANA) levels were positive in $16.8 \%$ of the patients with CSU and $6.5 \%$ of the children had positive thyroid autoantibody. Urinary tract infection was found in $3 \%$ of the patients. $1.9 \%$ of the patients with CSU were positive for helicobacter pylori and $1.9 \%$ of the patients had positive stool examination results for parasites. The mean UAS7 was $12.96 \pm 9.8$ and the mean UCT was $8.43 \pm 2.8$. No significant difference was found between the groups in terms of age, gender, presence of angioedema, duration of disease and ANA positivity when compared with control $(n=24)$ and uncontrolled $(n=83)$ patients (respectively, $p=0.842, p=0.646, p=0.347, p=0.590, p=0.316)$. Conclusion: In children, atopic diseases, infections, parasitic infestations are present in the etiology of CSU, whereas in most cases the diagnosis remains idiopathic.
\end{abstract}

Key words: Chronic urticaria, childhood, autoimmune thyroiditis, urticaria control test, urticaria activity scoring.

Serkan F. Evaluation of clinical and demographic data of children with chronic spontaneous urticaria in Antalya province. Pam Med J 2020;13:129-135.

Serkan Filiz, MD. Sağlık Bilimleri Üniversitesi Antalya Eğitim ve Araştırma Hastanesi, Çocuk Allerji ve İmmünoloji Kliniği, ANTALYA, e-posta: serkanfiliz75@gmail.com (orcid.org/0000-0002-7733-9067) (Sorumlu Yazar) 


\section{Giriş}

Ürtiker sık görülen ve aniden ortaya çıkıp aynı gün içinde kendiliğinden kaybolan kaşıntılı ve ödemli plaklar ile karakterize değişik nedenler ve farklı mekanizmalarla ortaya çıkan heterojen bir deri hastalığıdır [1, 2]. Altı hafta ya da daha uzun süren klinik tablolar " Kronik Ürtiker " (KÜ) olarak adlandırıır [3]. KÜ, "kronik spontan ürtiker (KSÜ)" ve belirlenebilir fiziksel veya diğer uyarıcıların varlığında ortaya çıkan ürtikerler "uyarılabilir ürtiker" olarak iki alt gruba ayrılır. Kronik spontan ürtiker, konusundaki epidemiyolojik veriler değişkenlik göstermekle birlikte çocukluk çağında \%0,10,3 sıklıkla görülmektedir [4, 5]. Birçok KSÜ spontan olarak düzelebilmekle birlikte, bazı formlarında hastaların yaşam kalitesini belirgin olarak olumsuz etkilemekte ve sosyo-ekonomik sorunlara yol açabilmektedir $[6,7]$.

Kronik ürtiker ile ilgili yapılan çalışmalar genellikle erişkin çalışması olup çoğunluğunda etiyoloji idiyopatiktir [2, 8, 9, 10]. Ülkemizde çocukluk çağında KSÜ konusunda yapılmış, çok merkezli çalışmalar azdır ve genellikle tek merkez deneyimi şeklinde çalışmalar mevcuttur $[11,12,13]$. Otoimmünite, atopik hastalıklar, enfeksiyonlar, paraziter enfestasyonlar, tiroid hastalıkları genellikle gösterilen nedenler arasında olup çoğu vakada tanı idiyopatiktir.

Antalya ilimizde çocukluk çağında KSÜ ile ilgili yapılmış bir çalışma bulunmamaktadır. $\mathrm{Bu}$ çalışmanın amacı kliniğimizde KSÜ tanısı alan hastaların klinik ve demografik verilerinin, laboratuvar bulgularının ve olası etiyolojik faktörlerinin araştırımasıdır.

\section{Gereç ve yöntem}

Antalya Eğitim ve Araştırma Hastanesi Çocuk Alerji-İmünoloji Kliniği'nde Mayıs 2017-Nisan 2018 tarihleri arasında KSÜ tanısıyla izlenen yaşları 7-17 yaş arasındaki 107 çocuğun kayıtları retrospektif olarak değerlendirildi. Çalışma için Antalya Eğitim ve Araştırma Hastanesi Klinik Araştırmalar Etik Kurul'undan onay alındı. Hastaların kayıtlarından yaş, cinsiyet, alerjik hastalıklar, ürtiker süresi, anjioödem varlığı, tetikleyici faktörler, fizik muayene bulguları, ürtiker aktivite skorları (ÜAS), ürtiker kontrol testi (ÜKT), laboratuvar bulguları ve aldığı tedaviler değerlendirildi.
Laboratuar testleri olarak tam kan sayımı, karaciğer fonksiyon testleri, eritrosit sedimentasyon hızı, C3-C4 düzey, idrar tetkiki, total $\lg E$ düzeyi, besin ve inhalen spesifik $\lg E$ düzeyleri, anti-nükleer antikor (ANA), tiroid fonksiyon testleri, anti-tiroglobulin ve antiperoksidaz otoantikorları, gaita serolojisi, gaitada Helikobakter pylori antijeni ve idrar kültürü değerlendirildi. Akut ürtiker ve uyarılabilir ürtiker tanısı alan hastalar çalışma dışı bırakıldı.

Hastaların serum spesifik IgE düzeyleri ImmunoCAP metodu (Phadia, Uppsala, İsveç) ile çalışıldı. Besin ve inhalan spesifik IgE $>0,35 \mathrm{kU} / \mathrm{l}$ değerleri pozitif olarak değerlendirildi. Klinik ile pozitif laboratuvar testleri arasında anlamlı ilişki varsa alerji olarak kabul edildi, besinler için ek provokasyon testleri uygulanmadı. Çalışmaya alınan tüm hastalara Ürtiker Aktivite Skoru (ÜAS) ve Ürtiker Kontrol Testi (ÜKT) rutin olarak uygulandı.

\section{Ürtiker aktivite skoru (ÜAS)}

Hastalık şiddetinin değerlendirilmesi için kabarıklık ve kaşıntı şiddetini içeren Ürtiker Aktivite Skoru (ÜAS) kullanıldı. ÜAS, günlük olarak kabarıklık sayısını ve kaşıntı şiddetini içermekte idi ve hastanın vizitler arasında nasıl olduğunu değerlendirebilmek için son 7 günü içeren ÜAS7 skorlaması kullanıldı. ÜAS7: Yedi günlük Ürtiker aktivite skoru; toplamı (minimum 0 -maksimum 42). ÜAS7 skorunun $\leq 6$ olması iyi kontrollü, 7-15 arası olması hafif, 16-27 arası olması orta ve 28-42 olması ise şiddetli ürtiker olarak değerlendirildi [2] (Ek 1).

\section{Ürtiker kontrol testi (ÜKT)}

Ürtiker kontrol testi, Weller ve arkadaşları [14] tarafından önerilen bir skor kullanılarak değerlendirildi. Her ÜKT maddesinin 5 cevap seçeneği vardı (0-4 puan). Düşük noktalar yüksek hastalık aktivitesini ve düşük hastalık kontrolünü göstermekte idi. ÜKT doğrulama aşamasında, ÜKT puanı 4 ayrı öğe puanının eklenmesiyle hesaplandı. Buna göre, minimum ve maksimum ÜKT skorları 0 ve 16 idi ve 12 ve üstündeki değerler tam hastalık kontrolünü göstermekte idi [15] (Ek2).

Antihistamin dozları, yanıt alınamayan durumlarda, çocuğun yaş ve kilosu dikkate alınarak tek doz şeklinde başlayıp gerektiğinde 2-4 katına kadar çıkıldı. 


\section{İstatistiksel analiz}

İstatistiksel analiz SPSS (20.0, SPSS Inc, Chicago, Illinois, ABD Sosyal Bilimler için İstatistik Paketi) kullanılarak yapıldı. Sürekli değişkenler parametrik testler için ortalama \pm standart sapma ve parametrik olmayan testler için ortanca (minimum-maksimum) olarak tanımlandı. Kategorik değişkenlerin karşılaştırılmasında ki-kare testi kullanıldı. İki grubun değerleri arasındaki farkın analizinde, normallik hipotezi Shapiro-Wilk testi ile test edildi. Normal dağılım gösteren parametreler için Student t-testi kullanıldı ve normal dağılımda olmayanlar için Mann Whitney U-testi kullanıldı. Değişkenler arasındaki ilişkiler Spearman korelasyon katsayısı kullanılarak hesaplanmıştır. $P<0,05$ istatistiksel olarak anlamlı kabul edilmiştir.

\section{Bulgular}

Kronik spontan ürtiker tanısı ile izlenen 107 hasta çalışmaya alındı. Hastaların ortalama

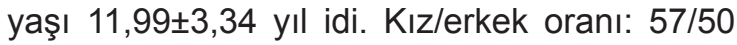
idi. Hastaların \%66'sına anjioödem eşlik etmekteydi. Ürtiker ortanca süresi 8 (2-72) ay idi. Hastaların \%36'ına allerjik hastalıklar eşlik etmekte idi. Hastaların \%12'sinde astım ve $\% 21$ 'inde alerjik rinit öyküsü vardı. 32 (\%33) hastada inhalen duyarlılığı ve $7(\% 6,5)$ hastada besin alerjen duyarlıı̆̆ı (2'sinde yumurta, 2'sinde fıstık, 1'inde kakao, 1'inde çilek, 1 'inde süt) saptandı (Tablo 1). Kronik ürtikerli hastaların \%36'sinde atopi, \%48'sinde IgE yüksekliği (lgE>100 KU/L) ve \%10'unda eozinofili (eosinofil yüzdesi $>\% 4$ ) tespit edildi. Hastaların $\% 16,4$ 'ünde ANA pozitifliği saptanmasına karşın hiç bir hasta romatolojik bir hastalık tanısı almadı. Tiroid otoantikor pozitifliği saptanan $7(\% 6,5)$ hastanın takipte 1 tanesi otoimmun tiroidit tanısı aldı ve Çocuk Endokrin tarafından Levotiroksin tedavisine başlandı. İki $(\% 1,9)$ hastada Helikobakter pylori pozitifliği ve kronik gastrit yakınması varken $2(\% 1,9)$ hastada dışkıda parazit (Blastocystis hominis ve Giardia intestinalis) saptandı. Tüm hastaların karaciğer ve böbrek fonksiyon testleri normaldi. Hiçbir hastada anormal hepatit serolojisi saptanmadı. Anormal idrar analizi tespit edilen 8 hastanın 3 'ünde idrar kültüründe üreme gözlendi (Tablo 2). ÜAS ortalaması $12,96 \pm 9,8(0-36)$ ve ÜKT ortalaması 8,43 $\pm 2,8$ (3-20) idi. ÜAS7'ye göre 26/73/ (\%35,6) hastada ürtiker iyi kontrollü, $22 / 73(\% 30,1)$ hasta hafif, 14/73 (\%19,2) hastada orta ve $11 / 73(\% 15,1)$ hastada şiddetli ürtiker yakınması vardı. ÜKT skorlamasına göre $24(\% 22,4)$ hastada ürtiker kontrollü olarak tespit edildi. ÜKT kontrollü $(n=24)$ ve kontrolsüz $(n=83)$ olan hastalar karşılaştırıldığında, yaş cinsiyet, anjioödem varlığı, hastalık süresi ve ANA pozitifliği açısından gruplar arasında anlamlı bir fark saptanmadı (sırasıyla, $p=0,842$, $p=0,646, p=0,347, p=0,590, p=0,316$ ) (Tablo 3). ÜAS7 etkileyen faktörler incelendiğinde benzer şekilde, yaş cinsiyet, anjioödem varlığı, hastalık süresi ve ANA pozitifliği açısından anlamlı bir fark saptanmadı (sırasıyla, $p=0,752, p=0,499$, $p=0,522, p=0,344, p=0,074)$.

Hastaların tamamı ikinci kuşak $\mathrm{H} 1$ antihistaminik tedavisi almaktaydı. Otoimmün tiroidit saptanan bir hastada levotiroksin tedavisi ile ürtiker kontrol altına alındı. Helikobakter pylori antijeni pozitif saptanan 2 hastaya eradikasyon tedavisi verildi ve remisyon sağlandı. Parazitoz saptanan 2 hastanın (1 hastada Giardia intestinalis, 1 hastada Blastocystis hominis) eradikasyon tedavisi sonrası ürtiker yakınmaları düzeldi. Beş hastaya ikinci kuşak $\mathrm{H} 1$ antihistaminik tedavisi yanında montelukast tedavisi başlanırken 3'ünde ürtiker kontrol altına alındı. Antihistaminik ile kontrol altına alınamayan 4 hastaya anti-lgE (omalizumab) tedavisi başlandı. Her iki hasta 4 ay omalizumab tedavisi aldıktan sonra tam remisyona girerken 2 hastada ikinci 4.ayda kontrol sağlandı ve tedavi 12.aya tamamlanarak kesildi. Yüz yedi hastanın sadece 68 tanesinin poliklinik takibine düzenli olarak devam ettiği ve bu hastaların 54'ünün $\mathrm{H} 1$ antihistaminik tedavi ile remisyonda olduğu görüldü. 
Tablo 1. Kronik spontan ürtikerli hastaların klinik ve demografik özellikleri.

\begin{tabular}{|c|c|}
\hline Cinsiyet (K/E) & $57 / 50$ \\
\hline Yaş (yıl) & $11,99 \pm 3,34$ \\
\hline Anjioödem varlığı, $\mathrm{n}(\%)$ & $66(61,7)$ \\
\hline Atopi varlığı, $\mathrm{n}(\%)$ & $39 / 107(36,5)$ \\
\hline Alerjik astım & $9 / 107(12)$ \\
\hline Alerjik rinit & $22 / 107(21)$ \\
\hline Hastalık süresi (ay) (Ortalama \pm Standart sapma) & $13,5 \pm 15,1$ \\
\hline \multicolumn{2}{|l|}{ Tedavi } \\
\hline Antihistaminik, $\mathrm{n}(\%)$ & $98 / 107(91,6)$ \\
\hline Antihistaminink + montelukast, $\mathrm{n}(\%)$ & $5 / 107(4,7)$ \\
\hline Antihistaminik + omalizumab, $\mathrm{n}(\%)$ & $4 / 107(3,7)$ \\
\hline 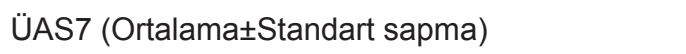 & $12,96 \pm 9,8$ \\
\hline 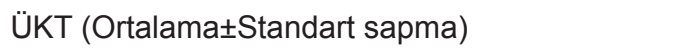 & $8,43 \pm 2,8$ \\
\hline
\end{tabular}

ÜAS7: Ürtiker Aktivite Skoru, ÜKT: Ürtiker Kontrol testi

Tablo 2. Kronik ürtikerli hastaların laboratuvar özellikleri.

\begin{tabular}{ll}
\hline Laboratuar parametresi & \\
Eozinofili (>\%4), n (\%) & $11 / 107(10)$ \\
IgE yüksekliği (>100 KU/L), n (\%) & $51 / 107(48)$ \\
İnhalan allerjen duyarlılığı, n (\%) & $32 / 107(33)$ \\
Besin allerjen duyarlılığı, n (\%) & $7 / 107(6,5)$ \\
Gaitada Helikobakter pylori pozitifliği, n (\%) & $3 / 51(5,8)$ \\
Gaitada parazit pozitifliği, n (\%) & $2 / 66(3)$ \\
Pozitif idrar kültürü, n (\%) & $3 / 107(2,8)$ \\
Anormal hepatit serolojisi, n (\%) & $0 / 107(0)$ \\
Anormal tiroid fonksiyon testi, n (\%) & $8 / 107(7,4)$ \\
Tiroid otoantikor pozitifliği, n (\%) & $7 / 107(6,5)$ \\
ANA pozitifliği, n (\%) & $18 / 107(16,8)$ \\
\hline
\end{tabular}

ANA, Anti nükleer antikor

Tablo 3. Ürtiker kontrol testini (ÜKT) etkileyen faktörler.

\begin{tabular}{llll}
\hline Değişkenler & $\begin{array}{l}\text { ÜKT kontrolsüz(ÜKT<12), } \\
\mathrm{n}=83\end{array}$ & $\begin{array}{l}\text { ÜKT kontrollü(ÜKT<12) } \\
\mathrm{n}=24\end{array}$ & $p$ \\
\hline Yaş & $12(7-17)$ & $11,5(7-18)$ & $0,842^{*}$ \\
Cinsiyet & 52 & & $0,646^{\#}$ \\
Kız & 40 & 14 & \\
Erkek & 49 & 10 & $0,347^{\#}$ \\
Anjioödem varlığı & 17 & $0,59^{*}$ \\
Hastalık süresi (median) & $6(6-60)$ & $12(2-72)$ & $0,316^{\#}$ \\
ANA pozitifliği & 16 & 2 & \\
\hline
\end{tabular}

ÜKT: Ürtiker kontrol testi, ANA: Anti nükleer antikor, * Mann-Whitney u test, * Ki-kare testi 


\section{Tartışma}

Çocukluk çağında kronik ürtiker ile ilgili literatür verisi sınırlıdır [4, 16]. Etiyolojisi ve patofizyolojisi hakkında bildiklerimizin büyük bir kısmı tek merkez deneyimleri şeklinde olup çocuklarda \%30-40 oranında etiyoloji tanımlanabilmekte ve \%60 kadarı idiyopatik olarak nitelendirilmektedir [11, 12, 17]. Biz bu çalışmamızda KSÜ'sü olan 107 hastanın klinik ve laboratuvar özelliklerini incelediğimizde $\% 58,8$ 'inde literatür ile uyumlu olarak etiyoloji saptayabildik. 107 hastanın \%61,7'inde literatür ile uyumlu olarak anjioödem saptandı. Çocukluk çağında kronik ürtikerli olguların \%40,158,1 'inde anjioödemin eşlik ettiği gösterilmiştir $[11,18]$.

Çalışmamızda olgularımızın \%33'ünde aeroalerjen duyarlılığı saptanırken, \%21'inde allerjik rinit ve \%12'sinde astım mevcuttu. Olgularımızın \%6,5'ine ise besin alerjisi eşlik etmekte idi. Sackesen ve ark. [19] ise kronik ürtikerli çocuklarda \%23,5 oranında aeroallerjen duyarlılığı \%12 oranında besin allerjen duyarlılığı saptamıştır. Azkur ve ark. [11] ise kronik ürtikerli çocukların \%12'sinde astım ve \%12'sinde alerjik rinit ve \%0,7'sinde besin alerjisi saptamıştır. Yaş grupları, cinsiyet ve bölgeler arasındaki farklılıklardan dolayı kronik ürtikere eşlik eden atopik hastalıkların sıklığında değişkenlikler görülebilir.

Kronik ürtikerin otoimmün doğasına ilişkin çalışmalar ağırlıklı olarak yetişkin populasyon çalışmaları olup çocuklarda, kronik ürtikerde otoimmünite sıklığı \%30 ile \%40 arasında değişmektedir [20-22]. Jirapongsananuruk ve ark.'nın [20] 94 KÜ tanılı çocukta yaptığı çalışmada sadece 2 hastada ANA titresi 1/160 üzerinde saptanmıştır. Ülkemizde yapılan bir çalışmada ANA pozitifliği 13/94 (\%13,8) oranında saptanmış olup, 1 tanesinin kollajen vasküler hastalıklar açısından takipte olduğu belirtilmiştir [12]. Bizim çalışmamızda 18/98 $(\% 16,8)$ hastada ANA pozitifliği ve 6 hastada ANA titresi>1/100 saptanmış olup hiçbirinde romatolojik hastalık ile uyumlu öykü ve fizik muayene bulgusuna rastlanmamıştır. ANA pozitifliği saptanan olgularımızda ANA pozitifliği ile ÜKT, ÜAS7 ve ürtiker süresi arasında bir ilişki gözlenmemiştir.

Yapılan çalışmalarda KÜ'lü hastalarda otoimmun tiroid hastalıkları prevelansı \%14-
29 oranında saptanmıştır [23-25]. KSÜ'lü hastalarda özellikle tiroit pereksidaz (TPO)'a yönelik IgG tipi otoantikorların varlığı gösterilmiş ve bu antikorların varlığı çocuklara göre erişkin hastalarda daha sık gözlenmiştir. Levotiroksin ve diğer tedavilerde ürtiker kontrolünün sağlanabildiği belirtilmiştir [23]. Bizim çalışmamızda 98 hastanın 7'sinde tiroit otoantikorları tespit edilirken bir hastanın Levotiroksin sonrası şikayetlerinin gerilediği gözlendi. Ülkemizde yapılan bir çalışmada 100 kronik ürtikerli hastadan 1 tanesinin Hashimato tiroiditi tanısı aldığı ve tedavi sonrası remisyona girdiği bildirilmiştir [12].

Harris ve ark. KÜ'lü hastaların \%2'sinde infeksiyonlar ile KÜ arasında ilişki saptamıştır [26]. Çalışmamızda da infeksiyonlar (idrar yolu enfeksiyonları, Helikobakter pylori, paraziter infeksiyonlar ) ile KÜ arasında literatür ile benzer oranda (\%2) bir ilişki saptanmıştır.

Çocuklarda kronik ürtikerde enfeksiyöz nedenler akut ürtikerdeki gibi önemli bir yer tutmasa da son zamanlarda Helikobakter pylori enfeksiyonu ve paraziter hastalıklar ile kronik ürtiker arasındaki ilişkiyi destekleyen çalışmalar gösterilmiştir. Ülkemizde yapılan çalışmalarda kronik ürtikerli çocuklarda \%31,2-32,8 oranında Helikobakter pylori pozitifliği saptarken (C-14 üre nefes testi ile) çalışmamızda ise hastaların \%58'inde Helikobakter pylori antijen pozitifliği saptanmıştır (gaitada Helikobakter pylori antijeni ile) [11, 27].

Kronik ürtiker ile paraziter enfeksiyonlar (Giardia lamblia, Strongyloides stercoralis, Toxocara canis, Blastocystis hominis) arasında ilişki bildiren yakın dönem çalışmalar mevcuttur [28-30]. Çalışmaların üçte ikisinde KSÜ'de paraziter enfeksiyon sıklığı \%10 ve daha az oranda olduğu gösterilmiştir [30]. Yılmaz ve ark.nın [29] kronik ürtikerli çocuklarda \%10 oranında paraziter enfeksiyon saptanmışken, bizim çalışmamızda ise 2 (\%3) olguda paraziter hastalıklar saptanmıştır (Giardia intestinalis, Blastocystis hominis). Antiparaziter tedavi sonrası hastaların \%50'sinden fazlasında tedavi sonrasında KSÜ 'de düzelme olduğu belirtilmiştir [30]. Bizim 2 hastamızda da tedavi sonrasında ürtikerin kontrol edildiği görülmüştür.

Son yayınlarda KÜ tanılı olguların \%23-40 kadarında yüksek afiniteli lgE reseptörüne karşı IgG yapısında otoantikorlar ve \%5-9 kadarında 
da fonksiyonel anti IgE antikorları saptanmıştır. $\mathrm{Bu}$ durum kronik otoimmun ürtiker (KOÜ) olarak ifade edilmektedir. Otolog serum deri testi (OSDT) kronik otoimmun ürtiker tanısında tarama testi olarak kullanılabilmektedir. Kronik ürtikerli hastaların \%23-40'ında pozitif olmasına karşın pozitif OSDT tek başına otoimmün kronik ürtiker için spesifik değildir [31]. Ülkemizde OSDT pozitif ve OSDT negatif hastalar arasında yapılan çalışmalarda, yaş, cinsiyet, atopi, allerjik hastalık, otoimmün hastalık varlığı, ANA pozitifliği, tiroid otoantikor varlığı ve Helikobakter pylori pozitifliği açısından gruplar arasında anlamlı bir fark saptanmamıştır $[11,12]$.

Çalışmamızda etik ve teknik nedenlerden dolayı OSDT yapılmaması çalışmamızın eksik bir özelliğidir. Buna ek olarak hastalarda ÜAS7 ve ÜKT'lerinin değerlendirilmesi çalışmamızın güçlü yanlarıdır. Ülkemizde çocukluk çağında KSÜ'lü hastalarda ÜAS ve ÜKT'lerin değerlendirildiği çalışma sayısı azdır. KSÜ'lü çocuklarda lipoksin A4 düzeyini araştıran bir çalışmada ÜAS seviyesi günlük olarak hesaplanmış ve ortanca değeri $3(2,8-5)$ olarak saptanmıştır [32]. Bizim çalışmamızda son 7 günü içeren ÜAS7 kullanılmış ve ÜAS7 ortalaması 12,96 $\pm 9,8$ olarak saptanmıştır. Çocukluk çağında KSÜ sıklığı ve ürtiker aktivite skoru arasındaki ilişkiyi inceleyen başka bir çalışmada ÜAS7 değerlendirilmiş ve ÜAS7 ortanca değeri 28 (21-42) olarak hesaplanmıştır [33]. Bu çalışmada başlangıç ÜAS7>28 olanlarda, semptomların persistan olabileceği belirtilirken bizim çalışmamızda ÜAS7 ve ÜKT'lerine etki eden faktörleri incelediğimizde; yaş, cinsiyet, hastalık süresi, anjioödem varlığı ve ANA pozitifliği açısından anlamlı bir farklılık saptanmadı.

Sonuç olarak, çocukluk çağında kronik spontan ürtiker ender görülen bir klinik tablo olmasına rağmen, etiyolojisi ve patofizyolojisi hakkında bildiklerimiz çok azdır. Bölgemizde kronik spontan ürtiker tanısı alan olguların klinik ve demografik özelliklerini inceleyen çalışmamızda literatüre benzer şekilde enfeksiyon hastalıkları, alerjik hastalıklar, tiroid hastalıkları, parazit enfestasyonların yer aldığı görülse de çoğu vaka idiyopatik olarak kalmaktadır.

Çıkar ilişkisi: Yazarlar çıkar ilişkisi olmadığını beyan eder.

\section{Kaynaklar}

1. Zuberbier T, Maurer M. Urticaria: current opinions about etiology, diagnosis and therapy. Acta Derm Venereol 2007;87:196-205. https://doi.org/10.2340/000155550240

2. Zuberbier T, Aberer W, Asero R, et al. The EAACl/ GA(2) LEN/EDF/WAO Guideline for the definition, classification, diagnosis and management of urticaria: the 2013 revision and update. Allergy 2014;69:868887. https://doi.org/10.1111/all.12313

3. Kaplan AP. Clinical practice. Chronic urticaria and angioedema. N Engl J Med 2002;346:175-179. https:// doi.org/10.1056/NEJMcp011186

4. Bernstein JA, Lang DM, Khan DA, et al. The diagnosis and management of acute and chronic urticaria: 2014 update. J Allergy Clin Immunol 2014;133:1270-1277. https://doi.org/10.1016/j.jaci.2014.02.036

5. Greaves MW, Tan KT. Chronic urticaria: recent advances. Clin Rev Allergy Immunol 2007;33:134-143. https://doi.org/10.1007/s12016-007-0038-3

6. Baiardini I, Giardini A, Pasquali M, et al. Quality of life and patients' satisfaction in chronic urticaria and respiratory allergy. Allergy 2003;58:621-623.

7. Maurer M, Ortonne JP, Zuberbier T. Chronic urticaria: a patient survey on quality-of-life, treatment usage and doctor-patient relation. Allergy 2009;64:581-588. https://doi.org/10.1111/j.1398-9995.2008.01853.x

8. Van der Valk PG, Moret G, Kiemeney LA. The natural history of chronic urticaria and angioedema in patients visiting a tertiary referral centre. $\mathrm{Br} J$ Dermatol 2002;146:110-113.

9. Kozel MM, Mekkes JR, Bossuyt PM, Bos JD. Natural course of physical and chronic urticaria and angioedema in 220 patients. J Am Acad Dermatol 2001;45:387-391. https://doi.org/10.1067/mjd.2001.116217

10. Kulthanan K, Jiamton S, Thumpimukvatana N, Pinkaew S. Chronic idiopathic urticaria: prevalence and clinical course. J Dermatol 2007;34:294-301. https://doi. org/10.1111/j.1346-8138.2007.00276.x

11. Azkur D, Civelek E, Toyran $M$, et al. Clinical and etiologic evaluation of the children with chronic urticaria. Allergy Asthma Proc 2016;37:450-457. https://doi.org/10.2500/aap.2016.37.4010

12. Sahiner UM, Civelek E, Tuncer A, et al. Chronic urticaria: etiology and natural course in children. Int Arch Allergy Immunol 2011;156:224-230. https://doi. org/10.1159/000322349

13. Işık S, Arıkan Ayyıldız Z, Çağlayan Sözmen Ş, et al. Kronik ürtikerli olgularımızın etyolojik değerlendirmesi. Türkderm 2014;48:13-16. https://doi.org/10.4274/ turkderm.13334 
14. Weller K, Groffik A, Church MK, et al. Development and validation of the Urticaria Control Test: a patientreported outcome instrument for assessing urticaria control. J Allergy Clin Immunol 2014;133:1365-1372. https://doi.org/10.1016/j.jaci.2013.12.1076

15. Kaplan A, Ferrer M, Bernstein JA, et al. Timing and duration of omalizumab response in patients with chronic idiopathic/spontaneous urticaria. J Allergy Clin Immunol 2016;137:474-481. https://doi.org/10.1016/j. jaci.2015.08.023

16. Choi SH, Baek HS. Approaches to the diagnosis and management of chronic urticaria in children. Korean J Pediatr 2015;8:159-164. https://doi.org/10.3345/ kjp.2015.58.5.159

17. Volonakis M, Katsarou-Katsari A, Stratigos J. Etiologic factors in childhood chronic urticaria. Ann Allergy 1992;69:161-165.

18. Chansakulporn $S$, Pongpreuksa $S$, Sangacharoenkit $P$, et al. The natural history of chronic urticaria in childhood: a prospective study. J Am Acad Dermatol 2014;71:663668. https://doi.org/10.1016/j.jaad.2014.05.069

19. Sackesen C, Sekerel BE, Orhan F, Kocabas CN, Tuncer A, Adalioglu G. The etiology of different forms of urticaria in childhood. Pediatr Dermatol 2004;21:102108. https://doi.org/ 10.1111/j.0736-8046.2004.21202.x

20. Jirapongsananuruk $\mathrm{O}, \quad$ Pongpreuksa $S$, Sangacharoenkit $P$, Visitsunthorn $N$, Vichyanond $P$. Identification of the etiologies of chronic urticaria in children: a prospective study of 94 patients. Pediatr Allergy Immunol 2010;21:508-514. https://doi. org/10.1111/j.1399-3038.2009.00912.x

22. Kolkhir P, Borzova E, Grattan C, Asero R, Pogorelov $D$, Maurer M. Autoimmune comorbidity in chronic spontaneous urticaria: a systematic review. Autoimmun Rev 2017;16:1196-1208. https://doi.org/10.1016/j. autrev.2017.10.003

23. Kolkhir $P$, Metz M, Altrichter S, Maurer M. Comorbidity of chronic spontaneous urticaria and autoimmune thyroid diseases: a systematic review. Allergy 2017;72:1440-1460. https://doi.org/10.1111/ all. 13182

24. Leznoff A, Sussman GL. Syndrome of idiopathic chronic urticaria and angioedema with thyroid autoimmunity: a study of 90 patients. J Allergy Clin Immunol 1989;84: 66-71. https://doi.org/10.1016/0091-6749(89)90180-2

25. Cebeci F, Tanrikut A, Topcu E, Onsun N, Kurtulmus $\mathrm{N}$, Uras AR. Association between chronic urticaria and thyroid autoimmunity. Eur J Dermatol 2006;16:402405.

26. Harris A, Twarog FJ, Geha RS: Chronic urticaria in childhood. natural course and etiology. Ann Allergy 1983;51:161-165.
27. Akelma AZ, Cizmeci MN, Mete E, Tufan N, Bozkurt B. A neglected cause for chronic spontaneous urticaria in children: helicobacter pylori. Allergol Immunopathol (Madr) 2015;43:259-63. https://doi.org/10.1016/j. aller.2013.12.001

28. Demirci M, Yildirim M, Aridogan BC, Baysal V, Korkmaz M. Tissue parasites in patients with chronic urticaria. J Dermatol 2003;30:777-81. https://doi. org/10.1111/j.1346-8138.2003.tb00477.x

29. Arik Yilmaz E, Karaatmaca B, Sackesen C, et al. Parasitic infections in children with chronic spontaneous urticaria. Int Arch Allergy Immunol 2016;171:130-135. https://doi.org/10.1159/000450953

30. Kolkhir P, Balakirski G, Merk HF, Olisova O, Maurer M. Chronic spontaneous urticaria and internal parasites: a systematic review. Allergy 2016;71:308-322. https:// doi.org/10.1111/all.12818

31. Poddighe D, De Amici M, Marseglia GL. Spontaneous (autoimmune) chronic urticaria in children: current evidences, diagnostic pitfalls and therapeutic management. Recent Pat Inflamm Allergy Drug Discov 2016;10:34-39. https://doi.org/10.2174/187221 $3 \times 10666160219163502$

32. Dilek F, Özçeker D, Güler EM, et al. Plasma lipoxin A4 levels in childhood chronic spontaneous urticaria. Turk J Pediatr 2018;60:527-534. https://doi.org/10.24953/ turkjped.2018.05.009

33. Arik Yilmaz E, Karaatmaca B, Cetinkaya PG, Soyer O, Sekerel BE, Sahiner UM. The persistence of chronic spontaneous urticaria in childhood is associated with the urticaria activity score. Allergy Asthma Proc 2017;38:136-142. https://doi.org/10.2500/ aap.2017.38.4029

\section{Teşekkürler}

İstatistiksel analizlerde desteği için Dr. Meral Bilgilisoy Filiz'e teşekkürlerimizi sunuyoruz.

Etik onayı: Antalya il merkezinde kronik spontan ürtikeri olan çocukların klinik ve demografik verilerinin değerlendirilmesi 2019-042 isimli çalışma Antalya Eğitim ve Araştırma Hastanesi Klinik Araştırmalar Etik Kurul'undan 14/02./2019 tarih ve $5 / 10$ sayılı karar ile onay alındı. 